Andréa Matias Alves 1 Pedro Coura-Filho 1

\section{Avaliação das ações de atenção às mulheres sob violência no espaço familiar, atendidas no Centro de Apoio à Mulher (Belo Horizonte), entre 1996 e 1998}

\author{
Estimate of activity women's attention that are \\ constrained in the family environment, Attentive \\ in Centro de Apoio à Mulher (Center of Women's \\ Support), in Belo Horizonte, between 1996-1998
}

1 Centro de Pesquisas Rene Rachou/Fiocruz-MS. Av. Augusto de Lima 1.715 Barro Preto - 30190-002 Belo Horizonte - MG. matias@cpqrr.fiocruz.br. pcoura@cpqrr.fiocruz.br.
Abstract These study analyzed the politic of women assistance's victims by violence in environment familiar and assisted by the program Cidadania da Mulher (Women's Citizenship) in two projects "Benvinda" (Welcome) and "Casa Abrigo" (Sheltering home) in Belo Horizonte (MG), Brazil from 1996 to 1998. The data were obtained with half-open and pretested questionnaires, obtaining the mental representation of the support employees, users $10 \%(N=70)$ and technical team, besides biological and social data, life conditions of the original families of the users, causes and types of violence $(N=1529$ users) between 96 and 98. In conclusion, the data showed: a) the violence occur in by culture social and economic, aspects without determinate that only one aspect is a cause of the violence; $b$ ) these data suggest to do studies of analytical cases in and out of familiar space c) These Program is important as emergency political social. It is one reference service for Belo Horizonte population metropolitan area, and countryside of this state. The objective is the better relations between the familiar and these institutions, to preservation the human rights and building of citizenship.

Key words Domestic violence, Outpatient care, Public health
Resumo Este estudo analisou a política de assistência a mulheres vitimas de violência no contexto familiar e assistidas no Programa Cidadania da Mulher, através de seus dois projetos: Centro de Apoio à Mulher - "Benvinda" e Casa Abrigo - "Sempre Viva", em Belo Horizonte, entre 1996-1998. Os dados foram adquiridos através de questionários semi-abertos e pré-testados, obtendo-se a representação mental das equipes técnica e de apoio ( $N=14)$, e de $10 \%$ de usuárias do Centro de Apoio no período de 1997-1998 (N=70); além de dados biológicos, psicossociais e das condições econômicas das usuárias entre 1996 e 1998 ( $N=1529)$; causas e tipos de violência. Os dados revelam que: a) a violência tem aspectos culturais, sociais e econômicas; b) estes indicadores descritos sugerem realizar estudos de casos analíticos dentro e fora do espaço familiar, de forma a aprofundar as questões aqui apresentadas; c) o programa é importante como política social de emergência por ser um serviço de referência para a população de Belo Horizonte e sua região metropolitana, além de cidades do interior do Estado, buscando maior integração entre as famílias destas com as instituições, na preservação dos direitos humanos e na construção da cidadania.

Palavras-chave Violência doméstica, Assistência ambulatorial, Saúde coletiva 


\section{Introdução}

No século XX, a humanidade conquistou avanços científicos que possibilitaram acessos a entendimentos até então desconhecidos, gerando produções surpreendentes, como a "globalização" das raças, religiões, tecnologias, medicinas e do processo de produção econômico. Por outro lado, produziu maior distanciamento de categorias psicossociais, antropológicas e econômicas, tendo como pano de fundo as relações e diferenças sociais. Um dos maiores e talvez o mais complexo legado do século é o fenômeno da violência, "globalizado" em aspectos científicos, políticos e sociais, com conceitos amplos e dialéticos. O século XX construiu instrumentos de pensamentos diversos e suscetíveis de compreensão da violência em diversas tradições psicossociológicas, e assim, considerou-se no campo científico que não há teoria geral que não seja capaz de contribuir com um enfoque específico para análise da violência.

O processo de entendimento desse fenômeno gerou o que aqui chamamos de "globalização da violência”, diante da exigência de estudos e intervenções multidisciplinares permeando os campos jurídico, ético, psicossocial, antropológico, econômico, médico e outros da saúde coletiva, indicando para cada enfoque sua quota de contribuição e seus limites. Várias razões buscam explicar a diversidade dessas produções teóricas acerca deste tema, não havendo portanto um único conceito ou enfoque que dê conta isoladamente desse fenômeno; sabe-se que ele encontra-se inserido na vida de relações do indivíduo com o mundo das coisas, seu corpo e mente, seus contextos em grupos particulares como o familiar, escolar, social; e em espaços públicos como no trabalho, trânsito, organizações políticas e serviços de saúde.

\section{Violência e relações sociais entre gêneros}

A violência está presente em todas as comunidades. Arendt (1995) analisa a violência em relação ao poder e observa que são termos opostos: violência não é manifestação de poder. A afirmação absoluta de um significa a ausência de outro, portanto, violência destrói o poder, não o constrói. Poder é a essência de todo governo que corresponde à habilidade humana para agir em concerto e nunca é propriedade de um indivíduo, que pertence a um grupo e permanece em existência apenas na medida em que o grupo está unido. Ela não precisa de justificação sendo inerente à própria existência das comunidades políticas, mas precisa de legitimidade já que é de fato a essência de todo governo. Violência é por natureza instrumental, distinguindo-se aí seu caráter de dependência da orientação e da justificação pelo fim que almeja. E só se justifica quando for uma re-ação imediata, nunca uma ação.

No campo da saúde coletiva, a violência recebeu da Organização Mundial da Saúde (OMS, 1993) a denominação de "causas externas” na Classificação Internacional de Doenças (CID-10), mas desde 1980 tem sido reconhecida Como uma questão de saúde pública, não somente do ponto de vista dos traumatismos físicos, mas também sobre os sérios efeitos para a saúde mental de quem a sofre. E a Organização Pan-Americana de Saúde (OPAS, 1993) analisa que a violência pelo número de vítimas e a magnitude de seqüelas orgânicas e emocionais que produz, adquiriu um caráter endêmico e se converteu em um problema de saúde pública em vários países.

$\mathrm{O}$ termo gênero vem sendo empregado em várias instâncias da sociedade: "questões de gênero", "gênero e a política" etc. Uma produção teórica em torno do termo, especialmente "violência de gênero", vem crescendo nos meios acadêmicos e nas práticas das políticas sociais. Não pretendemos aqui conceituar ou reproduzir os já elaborados conceitos que a palavra gênero traz consigo, mas lembremos o que Ferreira (1986) nos diz: Gênero é a categoria que indica, por meio de desinências, uma divisão dos nomes baseada em critérios tais como sexo e associações psicológicas e aponta o gênero masculino, feminino e o neutro. Algumas premissas são consideradas em torno das elaborações teóricas usadas que se referem ao gênero: 1) exploração das continuidades/descontinuidades das desigualdades presentes, das experiências sociais radicalmente diferentes; 2) constatação da alta qualidade dos trabalhos sobre a história das mulheres e seu estatuto marginal em relação ao conjunto das disciplinas; 3 ) um desafio teórico, exigindo a análise não só da relação entre as experiências masculinas e femininas mas também a ligação entre a história do passado e as práticas históricas atuais. 


\section{A família mineira}

Abordar a família implica examinar o sujeito concretamente constituído, concebendo a individualidade/subjetividade como um processo construído socialmente a partir de um contexto ambiental caracteristicamente heterogêneo. Elegemos pois, como idéia de contexto: as relações pessoa-contexto seriam um lugar real do desenvolvimento humano, enquanto estrutura aberta e dinamicamente mutável, existindo, ao mesmo tempo. Criados por pessoas, enquanto atores sociais, para além do indivíduo tomado isoladamente Por assim dizer, são marcos presentes no engendramento de novos modelos assistenciais no espaço da saúde coletiva, expressando-se em um leque de reformulações e envolvendo um rico exercício de (re)conceitualizações, em torno de termos como ecologia, espaço, território (Bastos, 1998).

A constituição familiar em Minas Gerais foi marcada por um conflito permanente entre os poderes da Igreja, conciliados aos interesses do Estado versus a cultura popular. As uniões consensuais constituíam um modo de vida familiar próprio dos setores intermediários e grupos populares que envolviam um número elevado de pessoas à margem do controle das autoridades da Igreja e do Estado. O convívio familiar nas uniões ilegítimas apresentava traços oscilantes entre dois extremos que se confundiam: a excessiva violência ou o amor excessivo; mulheres pouco passivas em seus papéis, atitudes de estabilidade contrárias à ordem escravagista e comprovações extremadas de afeto (Del Priore, 1997). A vida familiar era ainda acompanhada pela presença de crianças, um dos principais confrontos entre a ordem legal do Estado que defendia o princípio de que uma nação rica é uma nação abundantemente povoada; e da Igreja, contrária à cultura popular do concubinato, esforçada em definir nos povoados o modelo cristão de organização popular. Nesse cenário tem lugar o aparecimento da família fracionada como a mais perfeita síntese desse amplo processo cultural: casais abriam mão da coabitação para manter a união sem perigo da exclusão religiosa, e o Estado controlando os trabalhos de mineração, em última instância, garantia através do fisco e do comércio a transferência de rendas à economia metropolitana, forjada na manutenção da família como unidade de produção, de agregação e de controle social.
Nos anos 50 do século XX, o Brasil viveu um período de ascensão da classe média, com possibilidades de acesso à informação, ao lazer e ao consumo. As condições de vida nas cidades diminuíram muitas das distâncias entre homens e mulheres. Práticas sociais, do namoro à intimidade familiar, também sofreram modificações. Na família-modelo dessa épo$\mathrm{ca}$, os homens tinham autoridade e poder sobre as mulheres e filhos e eram responsáveis pelo sustento da família. Em menor proporção, a família influenciava na escolha matrimonial seguindo padrões de comportamentos norte-americanos e o casamento-modelo definia atribuições e direitos distintos para homens e mulheres.

Na segunda metade da década de 1970, o divórcio passa a fazer parte das leis brasileiras sob forte oposição da Igreja. A crise dos anos 80 e 90 atrai cada vez mais núcleos familiares para o centro urbano reforçando as características de urbanismo e solidariedade da família mineira, que se (re)organiza internamente para aplicar-se ao desempenho de dois tipos de trabalho que se impõem: o de provisão e o doméstico, ampliando os bolsões de pobreza e miséria na metrópole (Santos, 1997a), recorrendo à religiosidade em busca de apoio psicológico e apaziguamento das situações de crises vividas. Faz parte desse processo, o crescimento da violência urbana e suas várias manifestações, hoje um fenômeno universal, e que tem sido tratado de diferentes maneiras em cada sociedade.

Em Minas Gerais, como em todo o Brasil, a magnitude da violência familiar ainda não pode ser bem dimensionada. O reconhecimento recente do problema, a utilização de diferentes definições do fenômeno pelas instituições e pesquisadores responsáveis pelas estatísticas disponíveis, a diversidade das fontes de informação existentes e a inexistência de inquéritos populacionais nacionais são alguns dos fatores que dificultam estimativas mais acuradas (Reichenheim et al. 1999a), além do que, acompanhamentos de casos de violência no contexto familiar exigem a participação multidisciplinar evitando escutas e ações compartimentalizadas. Belo Horizonte foi fundada em 12 de dezembro de 1897 quando tornou-se a capital do Estado de Minas Gerais. Está localizada ao norte da serra do Curral e tem uma área de $335,5 \mathrm{~km}^{2}$ que abrigou uma população de 2.091.448 habitantes em 1996, segundo o Instituto Brasileiro de Geografia e Estatística (IBGE,1996). 
O processo de ocupação da cidade, no início do século, foi muito além do previsto e desde então tornou-se preocupante. Apareceram os sinais de crescimento descontrolado, revelando problemas urbanos bem parecidos com os atuais. As favelas, apesar de presentes desde os primeiros anos, tornaram-se significativas a cada década. Dois dos problemas mais graves da capital mineira são a população crescente e a falta de infra-estrutura urbana na periferia. $\mathrm{Na}$ área central, a violência da luta entre veículos e pedestres dá o título à cidade de recordista em atropelamentos, o que desde 1996, vem sendo trabalhado pela prefeitura com um plano-diretor para o caos do trânsito. A cidade possui em sua região metropolitana $33 \mathrm{mu}-$ nicípios, totalizando 3.803.249 habitantes (IBGE, 1996). A capital está subdividida em nove administrações regionais: Barreiro, Centro-Sul, Leste, Norte, Nordeste, Noroeste, Oeste, Pampulha e Venda Nova, que apresentaram taxas de crescimento do PIB em 1998 num total de -1,4\% (Fundação João Pinheiro, 1998). Para o setor de educação são 812 estabelecimentos de ensino particulares e públicos. Na saúde, na rede ambulatorial encontramos 126 centros de saúde, nove policlínicas, três unidades de urgência, quatro unidades de referência especializadas, dois centros de referência para a saúde mental, um pronto-socorro municipal e 157 hospitais públicos, filantrópicos e privados. Encontram-se ainda no município diversas atividades de cultura/lazer/turismo e parques ecológicos, rede de comunicação de massa, transportes intermunicipais, interestaduais e internacionais (Secretaria Municipal de Planejamento, 1999). Como resposta a esse quadro de aparecimento da violência no espaço urbano de Belo Horizonte, os serviços de atenção às mulheres sob violência do município tiveram origem em 1993, com a implantação do programa Cidadania da Mulher através da Secretaria Municipal de Desenvolvimento Social, com os seguintes objetivos: a) identificar demandas de ordem jurídica, psicossocial e antropológica de mulheres residentes na capital; b) projetar e coordenar políticas públicas referentes aos direitos humanos com ênfase na violência familiar, saúde da mulher, educação e habitação; c) elaborar e implementar formas de parcerias interinstitucionais nos atendimentos propostos. Esse Programa, atualmente em processo de transformação pela Coordenadoria Municipal dos Direitos da Mulher, contém dois projetos: o Centro de Apoio à Mulher -
"Benvinda" e a Casa Abrigo "Sempre Viva", ambos idealizados e implementados com a participação efetiva de organizações populares, políticas, jurídicas e de moradoras, para atuarem com recursos públicos, tornando-se serviço de Estado. Isto caracteriza o progressivo entendimento e concretização da sociedade brasileira frente ao grave problema da violência familiar, passa a haver, ainda que reconhecidamente nos seus primórdios, uma crescente demanda por ações que a enfrentem. Surge também uma excelente oportunidade de se criar um ambiente onde as políticas e ações sanitárias para o enfrentamento do problema passem a se articular intimamente a programas de investigação, não importando se dentro ou fora de academias (Reichenheim, 1999b).

O surgimento do "Benvinda" e da Casa Abrigo "Sempre Viva”, através da participação popular, reforça a luta da população pela conquista dos direitos ao exercício da cidadania. Em nosso pais, tiveram papel fundamental para essa inclusão os movimentos sociais pela democracia, as instituições de direito, algumas organizações não-governamentais (ONGs) de atenção aos maus tratos na infância, e as organizações internacionais com poder de influenciar as pautas nacionais (Minayo \& Souza, 1999a). O "Benvinda" foi inaugurado em agosto de 1996, com o objetivo de atender, orientar e encaminhar, com recursos públicos, mulheres sob violência no espaço familiar, em suas necessidades jurídicas, sociais e psicológicas, quanto às questões do gênero feminino, especialmente a violência no contexto familiar.

Em junho de 1997, foi inaugurada a Casa Abrigo "Sempre Viva", destinada a atender mulheres e seus filhos menores, em caráter emergencial e provisório (90 dias), quando se avaliar situação de risco... oferecendo serviços de apoio psicológicos sociais e jurídico e de (re)colocação profissional quando possivvel (Gomes, 1995). Uma das ações dirigidas à prevenção de agressões futuras seria afastar do lar, em abrigos provisórios, crianças, adolescentes e mulheres vitimadas, em situação de risco de agressões mais graves, cujas intervenções de ajuda no seio da família já tenham sido esgotado (ou sejam impossíveis) (Cabral, 1999a).

A lógica dos serviços no "Benvinda" dá-se da seguinte forma: a) as usuárias primeiramente passam pelo serviço de acolhimento, e procedidos os encaminhamentos necessários; b) salvo os casos urgentes, a usuária é encaminhada ao serviço de pré-atendimento que tem 
como objetivo a formação de grupos de atendimentos visando à informação e principalmente à busca de conscientização no que tange não somente à situação "problema" mas, proporcionam o encontro com o próprio eu e com isso ser possivel um vislumbrar de horizontes diferentes daquele - a vitima, a pobrezinha a coitadinha (Ladeira, 1998). O pré-atendimento é realizado em dois encontros semanais sob coordenação da psicologia; c) o departamento de psicologia realiza atendimentos em grupos e individuais; d) o departamento jurídico responde pelas questões jurídicas com o propósito de orientar e encaminhar a usuária para as instituições competentes; e) as oficinas de pósatendimento funcionam como grupos terapêuticos e são oferecidas às usuárias que já passaram pelos atendimentos anteriores e são coordenadas pela psicologia.

\section{Metodologia}

Neste estudo mostramos uma análise descritiva de parâmetros biológicos, familiares e socioeconômicos de mulheres em situação de violência assistidas no Centro de Apoio à $\mathrm{Mu}$ lher - "Benvinda" e na Casa Abrigo "Sempre Viva”, no período de 1996 a 1998. Bem como, procuramos identificar a percepção das usuárias quanto aos atendimentos recebidos e dos funcionários quanto aos serviços prestados.

Os dados de Belo Horizonte foram obtidos da Secretaria de Estado de Segurança Pública, através da Delegacia Especializada de Crimes contra a Mulher (Tardieu, 1994-1995), instituição diretamente envolvida nos trabalhos do programa pesquisado. E os dados de Buenos Aires (Asuaje, 1997) foram propositadamente considerados neste estudo, devido às semelhanças encontradas tanto na organização técnica quanto na política gerencial com os serviços pesquisados.

Foram considerados os tipos de agressões ocorridas; origem e tipos de encaminhamentos direcionados ao programa; procedimentos adotados, assim como, o tempo de uso dos serviços e a situação de desligamento.

As informações foram obtidas através do levantamento das percepções das usuárias e dos funcionários quanto aos serviços recebidos e oferecidos respectivamente, e se encontram demostrados nas tabelas 3 e 4 .

Como instrumental para coleta desses dados, junto às usuárias, foram utilizados ques- tionários semi-estruturados, pré-testados aplicados ao universo de 10\% (70) das usuárias do Centro de Apoio no período de 1997 a 1998, sendo $28 \%$ (20) na forma de visitas domiciliares; $31 \%$ (22) através de questionário por postagem; e 42\% (30) questionários por telefone, obtendo no geral, 70\% (49) de respostas. Os dados apresentados nas tabelas 1,2 e 5 foram obtidos dos prontuários do programa.

Junto aos funcionários, foram ouvidos cada um dos 14 trabalhadores ativos no momento da realização da pesquisas, bem como as sete abrigadas no mesmo período.

\section{Resultados}

Na tabela 1 encontramos os parâmetros biológicos, familiares, sociais e econômicos das usuárias das quatro instituições estudadas sendo: $88 \%$ de usuárias do "Benvinda" e $86 \%$ da Casa Abrigo em idade produtiva para o mercado de trabalho e em idade fértil (16-48 anos). Quanto a cor, optamos por considerá-la "branca" e "não-branca". Encontramos no "Benvinda" e na Casa Abrigo, respectivamente, 38\% e $54 \%$ para mulheres "brancas" e $54 \%$ e $46 \%$ para aquelas consideradas “não-brancas”. Sobre a origem, 73\% das usuárias eram migrantes e 86\% eram naturais de Belo Horizonte. Quanto aos índices de escolaridade foi apurado $12,5 \%$ das usuárias analfabetas. Quanto à relação de trabalho, 97\% das usuárias dos serviços do "Benvinda" e 85\% da Casa Abrigo tinham trabalho remunerado com ou sem vínculo legalizado de trabalho.

Ainda na tabela 1 observamos que $70 \%$ das usuárias do Centro de Apoio vivem em situação de esposa, sendo 49\% legalizadas, 24\% informais , $5 \%$ de viúvas e $10 \%$ de solteiras. As famílias apresentam-se com $50 \%$ de mulheres-mães de até dois filhos e 30\% com até três filhos. Nota-se ainda, que tanto no "Benvinda" como na Casa Abrigo, 24\% declararam ser residentes na regional Barreiro e 30\%, em média, na região oeste da cidade. Ainda nesta variável encontramos 5\% e 19\% de usuárias moradoras de outros municípios no "Benvinda" e na Casa Abrigo respectivamente.

O estudo coletou dados referentes ao consumo de medicação de uso controlado e contínuo das usuárias e computou 63\% de consumidoras de ansiolíticos e antidepressivos.

A tabela 2 mostra o percentual dos dados apurados no "Benvinda", sendo 85\% de soli- 
Tabela 1

Parâmetros biológicos, familiares, sociais e econômicos que identificam mulheres sob violência no espaço familiar, atendidas em instituições públicas de Buenos Aires e Belo Horizonte, Delegacia Especializada em Crimes Contra a Mulher, Centro de Apoio à Mulher - "Benvinda" e Casa Abrigo "Sempre Viva".

\begin{tabular}{|c|c|c|c|c|}
\hline \multirow[t]{2}{*}{ Variáveis } & \multicolumn{3}{|c|}{ Populações estudadas } & \multirow[b]{2}{*}{$\begin{array}{c}\text { "Sempre Viva" } \\
(\mathrm{n}=26) \%\end{array}$} \\
\hline & $\begin{array}{c}\text { Argentina } \\
\text { Buenos Aires } 1 \\
(\mathrm{n}=534) \%\end{array}$ & $\begin{array}{c}\text { DECCM } 2 \\
(\mathrm{n}=534) \%\end{array}$ & $\begin{array}{c}\text { Brasil } \\
\text { "Benvinda"3 } \\
(\mathrm{n}=1529) \%\end{array}$ & \\
\hline \multicolumn{5}{|l|}{ Faixa etária } \\
\hline até 15 & 6 & 5 & 1 & - \\
\hline $16-26$ & 22 & 26 & 21 & 35 \\
\hline $27-37$ & 36 & 52 & 39 & 42 \\
\hline $38-48$ & 24 & 10 & 26 & 23 \\
\hline $49-59$ & 5 & 7 & 11 & - \\
\hline$>60$ & 6 & - & - & - \\
\hline \multicolumn{5}{|l|}{ Cor } \\
\hline branca & - & - & 38 & 54 \\
\hline não-branca & - & - & 62 & 46 \\
\hline \multicolumn{5}{|l|}{ Naturalidade } \\
\hline Belo Horizonte & - & - & 27 & 86 \\
\hline Fora de Belo Horizonte & 100 & - & 73 & 14 \\
\hline \multicolumn{5}{|l|}{ Escolaridade } \\
\hline analfabeta & 2 & 6 & 2 & 15 \\
\hline primário & 26 & 19 & 77 & 73 \\
\hline secundário & 16 & 13 & 20 & 12 \\
\hline superior & 10 & 2 & 2 & - \\
\hline \multicolumn{5}{|l|}{ Trabalho } \\
\hline remunerada (c/ e s/vínculo) & 42 & 61 & 97 & 85 \\
\hline desempregada & 31 & 38 & 3 & 15 \\
\hline não informa & 21 & - & - & - \\
\hline \multicolumn{5}{|l|}{ Estado civil } \\
\hline casada & 53 & $4-0$ & 49 & 19 \\
\hline solteira & 32 & - & 10 & - \\
\hline amasiada & 27 & 29 & 24 & 77 \\
\hline divorciada & 13 & 5 & 11 & 4 \\
\hline viúva & 2 & - & 5 & - \\
\hline \multicolumn{5}{|l|}{ Número de filhos } \\
\hline $0-2$ & 57 & 53 & 5 & 50 \\
\hline $3-5$ & - & 27 & 57 & 42 \\
\hline $5-10$ & - & 9 & 35 & 8 \\
\hline+10 & - & - & 1 & - \\
\hline \multicolumn{5}{|l|}{ Local de residência } \\
\hline Província de Buenos Aires & 100 & - & - & _- \\
\hline Barreiro & - & 12 & 24 & 24 \\
\hline Centro-Sul & - & 10 & 2 & 4 \\
\hline Leste & - & 17 & 7 & 4 \\
\hline Nordeste & _- & 15 & 2 & 4 \\
\hline Noroeste & - & 16 & 3 & 4 \\
\hline Norte & - & 8 & 2 & - \\
\hline Oeste & - & 4 & 37 & 27 \\
\hline Pampulha & - & 3 & 3 & 4 \\
\hline Venda Nova & _- & 3 & 14 & 11 \\
\hline outros municípios & - & - & 5 & 19 \\
\hline \multicolumn{5}{|l|}{ Medicação } \\
\hline ansiolítico e antidepressivo & - & - & 68 & 58 \\
\hline antidepressivo & - & - & 4 & 6 \\
\hline ansiolítico e antihipertensivo & - & - & 28 & 36 \\
\hline tratamentos psiquiátricos & - & 30 & - & - \\
\hline
\end{tabular}

1 Programa de Violência Familiar Del Consejo Provincial de La Familia Y Desarrollo Humano de La Provincia de Buenos Aires: ASUAJE, (1993).

2 Delegacia Especializada de Crimes Contra a Mulher de Belo Horizonte/MG 1994/95: TARDIEU, (1994/95).

${ }^{3}$ Centro de Apoio à Mulher "Benvinda". 5 Casa Abrigo "Sempre viva". 
citações de acompanhamentos psicológicos em grupo ou individual e $55 \%$ para aqueles exclusivamente jurídicos. Ainda na tabela 2, encontramos no "Benvinda", $80 \%$ de casos procedidos de instituições públicas, sendo 64\% de serviços de saúde da rede pública. Quanto aos procedimentos adotados, o Centro de Apoio registrou 54\% relacionados aos setores jurídicos e $11 \%$ de convites para negociações e acordos através da prática de mediação.

A tabela 3 apresenta resultados da entrevista com as usuárias apontando que as abrigadas buscavam novas perspectivas de vida, estavam satisfeitas com os atendimentos recebidos, mas também sentiam-se presas, sem liberdade. Mostravam ainda uma dependência institucional já que declararam sentir medo de não conseguirem resolver seus problemas sem o amparo da instituição, assim como, 55\% solicitaram atendimentos psicológicos individuais, indicando a necessidade de escuta especializada, porém remetendo-nos à possibilidade de que a abrigada seja tutelada e não assistida.

A tabela 4 apresenta os resultados das 14 entrevistas realizadas junto aos funcionários de apoio e equipe técnica, mostrando a percepção dos profissionais que atendem casos de violência, destacando a identificação deles com a complexidade da proposta institucional, visto que a equipe vem desenvolvendo suas atividades desde a inauguração dos projetos; por considerarem a prática institucional como de grande valor para o crescimento profissional e este como fator positivo no trabalho; apontam questões técnicas e administrativas como principais deficiências institucionais, o que nos indica uma necessidade da rede interinstitucional dos serviços. O corpo técnico sentiu falta de capacitação teórica da complexidade do objeto, assim como atendimentos psicoterápicos para a equipe de atendimento. Apontam também para a necessidade da participação familiar como fator de mediação nos atendimentos.

Observa-se na tabela 5 que $66 \%$ das abrigadas não chegaram ao período máximo de permanência na Casa Abrigo (90 dias) e 27\% ultrapassaram o período limite. Destas, $38 \%$ regressaram ao antigo lar e $62 \%$ fizeram outras opções. Observou-se que 55\% esperavam encontrar apoio psicológico nos atendimentos e

Tabela 2

Descrição dos atendimentos nos serviços de atenção à violência.

\begin{tabular}{|c|c|c|c|c|}
\hline \multirow[t]{2}{*}{ Variáveis } & \multicolumn{3}{|c|}{ Populações estudadas } & \multirow[b]{2}{*}{$\begin{array}{l}\text { "Sempre Viva" } \\
\quad(\mathrm{n}=26) \%\end{array}$} \\
\hline & $\begin{array}{c}\text { Argentina } \\
\text { Buenos Aires } 1 \\
(\mathrm{n}=534) \%\end{array}$ & $\begin{array}{c}\text { DECCM }^{2} \\
(\mathrm{n}=360) \%\end{array}$ & $\begin{array}{c}\text { Brasil } \\
\text { "Benvinda"3 } \\
(\mathrm{n}=1529) \%\end{array}$ & \\
\hline \multicolumn{5}{|l|}{ Solicitação de serviço } \\
\hline psico-sócio-jurídico & 37 & - & 23 & - \\
\hline psicológico & 25 & - & 85 & - \\
\hline psicológico em grupo & - & - & 39 & - \\
\hline psicológico individual & - & - & 46 & - \\
\hline jurídico & 21 & 100 & 55 & - \\
\hline \multicolumn{5}{|c|}{ Origem do encaminhamento } \\
\hline familiares e amigos & 9 & - & 20 & - \\
\hline instituição pública & 33 & - & 80 & - \\
\hline iniciativa própria & 42 & - & - & - \\
\hline serviços de saúde & - & - & 64 & - \\
\hline centro de apoio & - & - & - & 100 \\
\hline \multicolumn{5}{|l|}{ Procedimentos } \\
\hline jurídico & - & - & 54 & - \\
\hline acordo & - & - & 11 & - \\
\hline orientações & - & - & 22 & - \\
\hline abrigo público & - & 45 & 7 & - \\
\hline
\end{tabular}

1 Programa de Violência Familiar Del Consejo Provincial de La Familia Y Desarrollo Humano de La Provincia de Buenos Aires: ASUAJE, (1993).

2 Delegacia Especializada de Crimes Contra Mulher de Belo Horizonte/MG,1994/95: TARDIEU, (1994/95).

3 Centro de Apoio à Mulher "Benvinda".

4 Casa Abrigo "Sempre Viva". 
Tabela 3

Percepção das usuárias sobre a qualidade dos serviços.

\begin{tabular}{|c|c|}
\hline Questões & Observações \\
\hline 1 - O que a senhora esperava encontrar quando & 1 - Institucional \\
\hline foi encaminhada à Casa Abrigo? & Estou aqui há 25 dias e ainda não tive nenhuma \\
\hline 4/7 uma nova perspectiva de vida & posição sobre audiência nem mesmo consigo ver \\
\hline 2/7 um lugar para se esconder & $\begin{array}{l}\text { meus filhos; estou esperando com paciência, porém } \\
\text { às vezes sinto que o processo aqui é lento não sei, }\end{array}$ \\
\hline $\begin{array}{l}2 \text { - Como a senhora avalia a assistência recebida? } \\
\text { a) na secretaria: }\end{array}$ & mais gostaria de uma resposta mais concreta. \\
\hline 4/7 ótima & Podia montar uma cooperativa com as mulheres, \\
\hline $2 / 7$ boa & de salgado, doces ou de lavar roupas ou de outras \\
\hline $\begin{array}{l}\text { b) nas demais dependências da Casa: } \\
\text { 3/7 ótima }\end{array}$ & coisas que a gente sabe fazer. \\
\hline $2 / 7$ boa & $\begin{array}{l}\text { mais empenho nos processos jurídicos, não } \\
\text { demorar tanto para acontecer as audiências. }\end{array}$ \\
\hline $\begin{array}{l}3 \text { - Durante o período de estada na Casa o que } \\
\text { a senhora observa com relação a si mesma? }\end{array}$ & 2 - Técnico/Profissional \\
\hline $\begin{array}{l}\text { 2/7 necessidade de mudança nas suas atitudes } \\
\text { com a sua família }\end{array}$ & $\begin{array}{l}\text { Eu gostaria que quando eu sair da Casa Abrigo eu } \\
\text { possa realmente ser feliz, não sofrer mais nenhum }\end{array}$ \\
\hline $\begin{array}{l}\text { 2/7 necessidade de mudança nas suas atitudes } \\
\text { consigo mesma } \\
\text { 2/7 sensação de estar presa, sem liberdade }\end{array}$ & $\begin{array}{l}\text { tipo de violência, poder contar com a ajuda dos } \\
\text { profissionais da casa e não me sentir sozinha e nem } \\
\text { desamparada conto com vocês. }\end{array}$ \\
\hline
\end{tabular}

4 - O que este período de estada na Casa traz de positivo para a senhora?

3/7 certeza de poder contar com o apoio de outras pessoas para solução de seus problemas

2/7 perspectiva de construir uma nova maneira de viver

5 - O que este período de estada na Casa traz de negativo para a senhora?

3/7 medo de não conseguir resolver seus

problemas como lhe é desejado

2/7 sensação de prisão, de estar fugindo sem culpa

6 - Como a senhora avalia os atendimentos psicológicos recebidos?

3/7 ótimo

2/7 bom

2/7 regular

7 - Como a senhora avalia os atendimentos sociais recebidos?

2/7 ótimo

3/7 bom

$2 / 7$ regular

$8-\mathrm{O}$ que a senhora acrescentaria nos atendimentos recebidos?

$3 / 7$ mais atendimentos individuais em psicologia

2/7 mais rapidez nos atendimentos externos

Às vezes sinto que alguns me desprezam sem saber de minha vida (profissionais)

\section{2 - Técnico/Profissional}

Eu quando vim para a casa foi porque não tinha outro lugar para ir com os meus filhos e pensava que estaria pelo menos com a certeza de arrumar um emprego e voltar a seguir em frente mais vi que isto não é tão fácil assim e sem formas de trabalho como vamos manter nós e nossos filhos. Assim, minha sugestão era que todas que aqui passassem, fossem embora com um emprego e que não precisasse mexer com os familiares.

A minha sugestão, é que deveria deixar as pessoas quando chegar a casa, começar a trabalhar logo, que chegue a casa de abrigo, um psicólogo em tempo integral para as crianças, e mais passeios para os adultos e crianças nos finais de semana.

poder sair mais vezes da casa para procurar emprego.

os técnicos fazem o que podem pelas mulheres mas às vezes acho que esta casa é uma ilusão. 
Tabela 4

Percepção dos funcionários do "Benvinda"1 e "Sempre Viva"2.

\begin{tabular}{l} 
Questões \\
\hline 1 - O que você considera mais importante \\
no seu trabalho? \\
$5 / 14(36 \%)$ a questão do gênero \\
$5 / 14(36 \%)$ a prática profissional \\
2 - O que você apontaria como uma deficiência \\
técnica do atendimento? \\
6/14 (43\%) a falta de ouvir a família \\
5/14 (36\%) a falta de um feedback \\
3 - O que o desmotiva no seu trabalho? \\
5/14 (36\%) recursos técnicos desfavoráveis \\
5/14 (36\%) a percepção de inércia dos mecanismos \\
disponíveis
\end{tabular}

4 - O que você vê de positivo no seu trabalho? $6 / 14(43 \%)$ crescimento profissional 4/14 (28\%) uma intervenção na questão do gênero

5 - O que você aponta como principal deficiência institucional no seu trabalho?

$6 / 14(43 \%)$ questões salariais

4/14 (28\%) questões de infra-estrutura

$4 / 14(28 \%)$ problemas técnicos profissionais

6 - Você acredita que os atendimentos possam prevenir a violência familiar?

$6 / 14(43 \%)$ sim

7/14 (50\%) não

\section{Observações}

1 - Institucional

Recursos Humanos 4/14 (28\%)

Minha situação na instituição como voluntária me permite ações bem pontuais e de certa forma limitada.

Minha situação funcional dentro da instituição limita-me no sentido de não desempenhar minha especificidade

... tantos obstáculos encontrados tais como falta de pessoal..

...para melhorar a qualidade dos trabalhos, dentre outras coisas, aumento do quadro de pessoal técnico

Institucional: 5/14 (36\%)

Falta de reconhecimento e valorização dos profissionais que integram o programa

Pouca motivação dos técnicos devido ao pouco envolvimento da Secret. para com o Programa

Mais envolvimento do Programa com a sociedade nos trabalhos de prevenção

2 - Técnico/Profissional: 3/14 (21\%) que a instituição prioriza oficinas, palestras, grupos operativos com temas como: violência, separação, alcoolismo.

criação de projeto que acompanhe as mulheres pós abrigo.

necessidade de aprimorar a intercomunicação dentro e fora da prefeitura como emprego e habitação

Equipe Técnica: 5/14 (36\%)

É necessário implantar atendimentos psicológicos para equipe técnica que lida com a violência

Falta de uma leitura mais profunda da complexidade do objeto de trabalho, bem como suas implicações no cotidiano das mulheres

\footnotetext{
1 Centro de Apoio à Mulher "Benvinda" .
}

2 Casa Abrigo "Sempre Viva". 
39\%, solução através das leis; $69 \%$ sabiam que a instituição só atende mulheres e $31 \%$ não sabiam. Quanto às orientações recebidas nos atendimentos jurídicos, $57 \%$ avaliaram como suficiente; $15 \%$ disseram não-suficientes. Quanto à perspectiva do futuro, 76\% afirmaram serem necessárias mudanças nas atitudes pessoais; $29 \%$ acrescentariam ouvir familiares nos atendimentos; $47 \%$ não acrescentariam nada. Declararam sentir dificuldades: $2 \%$ na localização da instituição; $6 \%$ em não conhecer a instituição e 51\% não sentiram qualquer dificuldade. Para os atendimentos de forma geral, $72 \%$ consideraram satisfatório e $29 \%$ não-satisfatório.

\section{Discussão}

Procuramos comparar os dados apurados neste estudo com os da Delegacia Especializada de Crimes Contra a Mulher entre 1994 e 1995 e com o Programa de Violencia Familiar del Consejo Provincial de la Familia y Desarrollo Humano de la Provincia de Buenos Aires em 1993.

Este trabalho buscou analisar as ações de atenção às usuárias do Programa Cidadania da Mulher, através de descrições qualitativas e quantitativas de dados sobre violência no contexto familiar, onde, muitas vezes, mulheres são as principais vítimas. Para esses procedimentos foram adotadas respectivamente duas abordagens: 1a) elaborar conceitos sobre a violência como produto de inter-relações de pessoas que ocupam um mesmo espaço existencial, como o da família e suas relações sociais, visto que é impossível estudar este fenômeno isoladamente e com um único olhar; 2a) descrever dados coletados com mulheres submetidas a violência no espaço familiar e assistidas em ambulatório especializado ("Benvinda") e/ou albergadas temporariamente (três meses) em pensão protegida dos agressores (Casa Abrigo).

Esses aparelhos de Estado são equipamentos sociais a serviço da população de Belo Horizonte e de trinta e três municípios na região metropolitana da capital mineira que somam três milhões de habitantes. No processo de urbanização no Brasil, observou-se que, já nas primeiras décadas do século XX, o novo perfil industrial surge forte e com capacidades de atrair e manter as pessoas nos meios urbanos, ainda que, muitas vezes, em condições subu-
Tabela 5

Parâmetros que identificam o tempo de permanência e a condição do desligamento das usuárias no Centro de Apoio à Mulher - "Benvinda" e abrigadas na Casa Abrigo "Sempre Viva"

\begin{tabular}{lcc}
\hline Variáveis & $\begin{array}{c}\text { Benvinda }^{1} \\
(\mathrm{n}=1529) \%\end{array}$ & $\begin{array}{c}\text { Sempre Viva }^{2} \\
(\mathrm{n}=26) \%\end{array}$ \\
\hline Tempo de serviço & & \\
$\quad$ até 30 dias & 3 & 31 \\
$31-60$ & 4 & 31 \\
$\quad 61-90$ & 18 & 12 \\
$\quad+90$ & 75 & 27 \\
Situação do desligamento & & \\
$\quad$ ao antigo lar & - & 38 \\
ao novo lar & - & 62 \\
\hline
\end{tabular}

1 Centro de Apoio à Mulher "Benvinda".

2 Casa Abrigo "Sempre Viva".

manas. A grande cidade se tornou o lugar de numerosas atividades "economicamente marginais” do ponto de vista tecnológico, organizacional, financeiro, fiscal e de políticas públicas para atender uma população que não tem acesso aos empregos necessários, nem aos bens e serviços essenciais, e que, por isso são vítimas da expansão da crise urbana, ativado pelo crescimento populacional, empobrecimento crônico e degradação das condições de existência (Santos, 1996a).

A cidade, em si, sobretudo a grande cidade, detentora da industrialização como relação social, entendida como "processo social complexo" (Santos, 1996b), tornou-se criadora e reprodutora de bolsões urbanos de pobreza, tanto pelo modelo socioeconômico excludente como por sua estrutura física, que faz dos habitantes excluídos pessoas ainda mais dependentes da assistência do Estado e crescente palco de conflitos urbanos e familiares. A violência urbana é seu maior sintoma que, segundo Minayo (1999), durante a última década dizimou a população brasileira, em mais de um milhão de pessoas, vítimas de homicídios, acidentes (violência de trânsito e de trabalho) e suicídios. Uma cifra de anos potenciais de vida perdidos de uma magnitude muito maior do que a provocada por quase todas as agressões já vividas pela humanidade; mostrando ainda, que a população jovem, masculina, negra, semi-analfabeta, desempregada, com idade entre 16 e 30 anos, é a que vem apresentando nos últimos anos maior número de vítimas da violência urbana (Minayo \& Souza, 1999b). 
Quanto aos parâmetros biológicos, familiares, sociais e econômicos das usuárias das quatros instituições estudadas, observamos 88\% e $86 \%$ no "Benvinda" e na Casa Abrigo respectivamente, de mulheres em idade produtiva para o mercado de trabalho brasileiro e em idade fértil (16-48anos).

Sobre o perfil social deste grupo assistido e aqui estudado observou-se que era composto por $68 \%$ de mulheres "não-brancas" e $32 \%$ de "brancas", $70 \%$ das usuárias fizeram o ensino fundamental; nota-se que com instrução superior, em Buenos Aires, somou-se $10 \%$ e no Brasil não chegou a 2\%; $85 \%$ eram trabalhadoras remuneradas sendo $44 \%$ em relações informais e $23 \%$ com vínculo empregatício, $90 \%$ das mulheres são mães de até cinco filhos. Este perfil ressalta fatores socioeconômicos como pobreza e fome que forçam a precária subsistência, desencadeando grande número de crimes cometidos sob o império da necessidade. A miséria conduz ao roubo e à prostituição. A sociedade brasileira é uma das mais desiguais, uma das mais estratificadas que existem. Aqui se encontra a mais extrema pobreza ao lado da mais fabulosa riqueza (Chesnais ,1999). Este perfil aponta para uma nova função da mulher que além de mãe vem sendo convidada a ocupar também o lugar de arrimo financeiro na família moderna.

A distribuição espacial dos casos atendidos revelou uma correlação positiva entre número de casos e número de residentes. Na região do Barreiro, o maior bairro da cidade em extensão geográfica e o segundo em número absoluto de residentes, foi observado o maior índice de prevalência de casos atendidos, $24 \%$.

Simultaneamente, a região de Venda Nova, a segunda maior do município em extensão geográfica, número de bairros e área comercial, respondeu por $14 \%$ dos atendimentos. Isto nos remete a duas questões: a primeira se refere-se à localização dos serviços, lado oposto da sede do Centro de Apoio, dificultando o deslocamento das usuárias; e a segunda, é que está próxima de uma delegacia distrital com atendimento exclusivo a mulheres violentadas. Ou seja, os serviços estão mal distribuídos no espaço urbano quando cruzamos informações sobre as residências das usuárias e a localização dos serviços prestados. Um fator comum nas duas regiões que mais produzem casos de violência contra a mulher é o fato de que os dois distritos sanitários estão em regiões cuja função social é receber o maior fluxo de mi- grantes provenientes do interior do estado em busca de melhores oportunidades de melhoria da qualidade de vida. Isto faz destas regiões um seleiro de mão-de-obra, muitas vezes desqualificada e/ou desempregada. Observa-se também, que o atendimento na DECCM nas regionais Norte, Pampulha e Venda Nova, não chegou a $10 \%$, por não fazer parte da área de abrangência da delegacia estudada.

Ao pensarmos a ocupação desorganizada desse espaço como um sintoma da "industrialização" em um "processo social complexo" (Santos 1996c), deparamos com o fato de que a região metropolitana de Belo Horizonte, acolhe mais de três milhões de pessoas, em dependência direta da capital em serviços de saúde, ensino especializado, e significativamente, das políticas de atenção social. Além da localização pouco adequada desses serviços no espaço urbano municipal soma-se o fato de que receberam 5 e 19\% de usuárias da região metropolitana e de outros municípios, respectivamente.

Os projetos de atenção às mulheres sob violência, criados pelo movimento de mulheres, caracterizam-se como instituições não só de proteção e assistência jurídica, mas de reivindicação, em $85 \%$ dos casos, de assistência psicológica. Este percentual aponta o volume e a intensidade do sofrimento psíquico gerado e a solicitação das usuárias em serem ouvidas e socialmente atendidas. Os procedimentos adotados no período estudado apontaram $54 \%$ de encaminhamentos para serviços jurídicos interinstitucionais. Isto aponta para a necessidade de um esforço multi-institucional e transdiciplinar no enfrentamento da violência como sintoma social, tornando imprescindível contar com uma ampla rede de apoio social, composta por instituições de diversos setores como educação, saúde, justiça, segurança, cultura e trabalho, governamentais e não-governamentais, serviços estes que extrapolam a área jurídica.

Como acusa Cabral (1999b), a maioria dos trabalhos sobre a violência doméstica não analisa profundamente a relação psicodinâmica conflituosa existente no lar do agressor e da mulher vitimada, principalmente quando sabemos que nem sempre a mulher agredida é apenas vítima pacífica nas relações com seus componentes. Neste estudo apenas 11\% das usuárias se dispuseram a negociações e acordo. Ou seja, a prática da mediação não foi dominante, mas apontou para uma saída do confli- 
to agudo com participação das partes nos atendimentos, fortalecendo a busca de decisões, já que é sabido, que as situações de violência atingem a todos os integrantes da família gerando conseqüências que podem ser imediatas, de médio e longo prazo.

Situações de violência no espaço familiar, dificilmente são passíveis de prevenção, principalmente quando o círculo de acumulação das tensões, ausência do autocontrole e a explosão é indefinido e podendo ocorrer em graus variados. Desse modo, as instituições de proteção às mulheres e seus filhos menores em situação de risco são, por vezes, a única alternativa de prevenir outra(s) situação(ões) semelhante(s), mas não de prevenir a violência. Assim, concordamos então parcialmente com Cabral (1999c), que aponta como prevenção à violência familiar afastar do lar, em abrigos provisórios, crianças, adolescentes e mulheres vitimadas em situação de risco de agressões mais graves, cujas intervenções de ajuda no seio da família já tenham se esgotado (ou sejam impossíveis). Essas medidas, necessárias e oportunas, são paliativas quando tomadas isoladamente do contexto familiar e das relações interinstitucionais. Se observarmos que, em Belo Horizonte, as mulheres ficam em média 50 dias abrigadas e $62 \%$ das usuárias construíram um novo modo de vida após esse período de "proteção", seremos obrigados a admitir que as soluções para os problemas dessas famílias estão associadas ao risco da desagregação familiar e à necessidade de um elemento mediador de crises.

Como observamos neste estudo, na opinião das usuárias, a Casa Abrigo de Belo Horizonte protege e por vezes socorre as abrigadas, cabendo estarmos atentos ao estreito limite entre prevenir e socorrer, assistir e tutelar. Desse modo foi preocupação deste estudo o desenvolvimento dos recursos humanos do programa e destacamos o que Reichenheim (1999) aponta: os esforços merecem ser dirigidos visando à quebra efetivamente das barreiras disciplinares, fazendo com que essas equipes não sejam meros retalhos, integrados por profissionais primordialmente alocados nos seus tradicionais setores (pediatria, psicologia, enfermagem, serviço social etc.). É notório que capacitações teóricas e afinidades profissionais também são atributos indispensáveis nos atendimentos.

Concluindo, o estudo apontou para: a) a necessidade de maior integração interinstitu- cional visando à divulgação dos resultados dos projetos; b) a necessidade de capacitação continuada dos recursos humanos envolvidos; c) a importância do projeto como política pública de Estado, especialmente no que se refere à saúde mental, à participação familiar e ao abrigo protegido; e d) o fato de os serviços terem tido origem no seio da sociedade organizada sendo repassados para o poder público tornando-se um exemplo claro de uma conquista social.

Apontou ainda que outras frentes de análises são merecedoras de estudos mais aplicados, tais como: 1) o acolhimento das usuárias tanto no Centro de Apoio como na Casa Abrigo; 2) estudo da dinâmica, da estrutura e da composição familiar e do modo de vida das usuárias; 3 ) a representação do uso de psicofármacos por mulheres submetidas a situações de violência no contexto familiar; 4) estudos de casos clínicos durante e depois do abrigo; 5) análise do custo/benefício da Casa Abrigo; e 6) permite fazer uma análise sociohistórica da participação popular na implementação de políticas públicas como um exercício de cidadania.

\section{Considerações finais}

\section{As mulheres na organização dos serviços}

O movimento das mulheres contra a violência fortaleceu-se nas lutas feministas especialmente nas décadas de 1970 e 1980, levando aos meios de comunicação e à sociedade em geral os denominados "Crimes da paixão". Abordando os atos violentos como um problema social e de saúde pública, foram criados junto ao Estado órgãos específicos voltados aos problemas da violência familiar, contra as mulheres, as crianças e atualmente contra os idosos.

As mulheres marcam a história através de suas organizações, em um cenário onde emergem os conflitos sociais, entre a expansão industrial, urbanização acelerada e a dicotomia entre a oferta de emprego e a demanda, juntamente com o registro de diversos movimentos sociais integrados às relações sociais no meio urbano/rural e de várias ordens: por melhores condições de trabalho, salário, saúde, saneamento, direitos à participação nas decisões políticas partidárias, habitação, à terra produtiva entre outros. Especialmente no Bra- 
sil, no caso da mobilização das mulheres, destaca-se no campo político partidário a conquista do direito ao voto em 1932; nas relações de trabalho, a criação de organizações de caráter trabalhista voltadas à busca da igualdade no exercício dos direitos a férias anuais, descanso semanal remunerado, creches e outros que propagavam a transposição da cidadania regulada para a cidadania plena. $\mathrm{Na}$ área da saúde o processo se deu mais lentamente nas primeiras décadas, quando as trabalhadoras reivindicavam melhores condições de higiene nas fábricas.

Na segunda metade do século XX, surge um novo caráter de mobilização social privilegiando outras instâncias além dos sindicatos e do patriarcado, onde "categorias" do trabalho deixam de ser o centro da ação deslocando-se, em direção à família e à comunidade.

A idéia de cidadania plena surge depois dos anos 70 assumindo um caráter de construção social, afirmando a busca dos direitos à solução das questões sociais e à implantação de políticas públicas, estas entendidas como um campo de práticas com enfrentamento das desigualdades sociais, através de articulações de propostas institucionais do Estado através da sua prática e de seus agentes; da clientela estando ela organizada ou não como expressão das categorias excluídas em busca da dignidade e da sobrevivência, asseguradas no processo de construção da democracia.

É através da junção entre a herança histórica do sindicalismo e as lutas pela melhoria das condições de vida que se começou a perceber que a população trabalhadora engloba ambos os sexos, cada um com responsabilidades diferentes no seio da família. E, em relação à organização social das mulheres para a saúde, em 1975, o Ano Internacional da $\mathrm{Mu}$ lher desencadeou ações voltadas à saúde pública, forçando o Estado em 1984, a implantar o Programa de Assistência Integral à Saúde da Mulher (PAISM), precariamente adotado pelos municípios, e é a Constituição de 1988 o marco das conquistas dos movimentos de mulheres, onde $90 \%$ das reivindicações são aceitas na Carta.

Concomitante ao processo de construção da democracia, a sociedade brasileira vive um dos piores períodos de recessão econômica já registrado. Nos anos 80 e 90, décadas perdidas economicamente mas de consideráveis avanços políticos e sociais, a urbanização cresce intensa e desorganizadamente, elevando também os índices de violência urbana e no ambiente familiar, em especial nas metrópoles e grandes cidades, fazendo surgir gradativamente movimentos institucionais como aqueles voltados à violência contra a mulher, admitida como questão social urbana através da criação das 260 delegacias especializadas em crimes contra a mulher vinculadas às secretarias de Estado de segurança pública; das seis casas abrigo e dos diversos centros de orientações e apoio psicossociais e jurídicos; das produções teóricas nos meios acadêmicos, na busca do exercício do direito de cidadania; das diretrizes da Organização Mundial de Saúde (OMS) em 1980; e da Organização Pan-Americana de Saúde (OPAS) em 1993.

\section{Sintomatologia associada}

Os estudiosos do fenômeno da violência no contexto familiar, especialmente daquele que atinge as mulheres, estão de acordo que na maioria é detectado sinais e sintomas depressivos e ansiosos, perturbações do sono, (hipersônia e insônia) transtornos alimentares como a anorexia, a bulimia, a compulsão para comer, que favorece a obesidade, fobias, disfunções sexuais, manifestações psicossomáticas, alcoolismo e abuso de calmantes ( $\mathrm{Ca}$ bral, 1999d). Como externalidade desse processo observamos que $64 \%$ dos encaminhamentos ao Centro de Apoio foram provenientes de serviços de saúde da rede pública e já chegaram fazendo uso de ansiolíticos e antidepressivos.

É sabido que o atendimento de emergência é um poderoso indicador da violência que ocorre na cidade. É para lá que correm ou são levadas as suas vitimas em situação de trauma ou iminência de morte. Para muitas pessoas, é a única vez em que estará, como vítima de uma agressão, diante de um profissional de saúde. Em muitos casos, é um dos momentos em que a violência será declarada (Deslandes, 1999). Nesse sentido, Tancredi (1986) estudando o consumo de medicamentos psicofármacos em uma comunidade paulista, observou que o tipo de vínculo matrimonial pode estar associado a maiores ou menores níveis de ansiedade e, portanto, ao consumo de medicamentos tranqüilizantes. Mulheres na faixa etária de 30 a 50 anos despontam como maiores consumidoras de psicofármacos em decorrência, talvez, de um elevado nível de conflito psicológico diante das modificações de seu papel social. 
Os serviços de saúde mental da rede pública têm como prioridade o direcionamento à reforma psiquiátrica (neuróticos graves, psicóticos e egressos hospitalares). As "causas externas” ocupam o segundo lugar na transição epidemiológica no Brasil, observadas do ponto de vista da mortalidade (Minayo \& Souza, 1999c), e, apesar desses dados, o mais preocupante é que podem estar camuflando uma realidade maior: a de que a violência no contexto familiar está longe de ocupar um lugar de prioridade nos atendimentos da rede básica de saúde. Segundo Ducan et al. (1990) outros fatores como o excesso de demanda nos serviços públicos de atenção primária à saúde, ausência de mecanismos adequados de controle de medicamentos, excesso de liberdade publicitária da indústria farmacêutica, prescrição médica inadequada, ausência de outros mecanismos substitutivos para o ato médico somados à "solidariedade" entre usuárias em informar às "colegas" sobre "medicamentos bons" são aditivos que reforçam a medicalização do sofrimento psíquico.

\section{Agradecimentos}

Às usuárias do "Benvinda" e da Casa Abrigo que autorizaram este estudo com a consciência de estarem colaborando na construção da cidadania; aos profissionais das referidas instituições que gentilmente se dispuseram a participar voluntariamente deste estudo; à Coordenadoria dos Direitos da Mulher que muito empenhou na viabilização deste estudo com os votos de que este seja o princípio de uma aproximação multi-institucional produtiva; ao dr. Rodrigo Corrêa de Oliveira, chefe do Laboratório de Imunologia Molecular e Celular do CPqRR/ FIOCRUZ, pela sensibilidade em permitir o desenvolvimento deste projeto em seu laboratório. 


\section{Referências bibliográficas}

Arendt H 1995. Sobre violência. Ed. Relume-Dumará, Rio de Janeiro.

Asuaje J 1997. El problema em cifras. Salud en la comunidad 5: 40-43.

Bastos C 1998. A família enquanto contexto de desenvolvimento humano: implicações para a investigação em saúde. Ciência \& Saúde Coletiva 3(1): 106115.

Cabral MAA 1999 a, b, c, d. Prevenção da violência conjugal contra a mulher. Ciência \& Saúde Coletiva 4(1): 183-191.

Chesnais JC 1999. A violência no Brasil. Causas e recomendações políticas para a sua prevenção. Ciência \& Saúde Coletiva 4(1): 53-69.

Del Priore M (org.) 1997. História das mulheres no Brasil. Ed. Contexto, São Paulo. 678p.

Deslandes FS 1999. O atendimento às vítimas de violência na emergência: "Prevenção numa hora dessas?" Ciência e Saúde Coletiva 4(1): 81-94.

Ducan et al. 1990. Medicina ambulatorial - condutas clínicas em atenção primária, Editora Artes Médicas Sul Ltda., Porto Alegre, 503p.

Ferreira A 1986. Novo Dicionário da Língua Portuguesa. Fundação João Pinheiro, Belo Horizonte.

Gomes M 1995. Projeto de Implantação do "Centro de Apoio à Mulher" (mimeo).

Instituto Brasileiro de Geografia e Estatística 1986. Anuário Estatístico. Belo Horizonte.
Ladeira M 1998. Relatório do Departamento de Psicologia do "Benvinda" (mimeo).

Minayo M 1999. Cidadania: o contrário da violência. Jornal da ASFOC/Fiocruz. Ano XI.

Minayo M, Souza ER 1999 a, b, c. É possível prevenir a violência? Reflexões a partir do campo da saúde pública. Ciência \& Saúde Coletiva 4(1): 7-32

OMS 1993. Salud mundial. Genebra.

OPAS 1994. Resolução XIX: violencia y salud. Washington (mimeo).

Reichenheim ME 1999 a, b, c. Conseqüências da violência familiar na saúde da criança e do adolescente: contribuições para a elaboração de propostas de ação. Ciência \& Saúde Coletiva, 4(1):109-121

Santos M 1996 a, b, c. A urbanização brasileira (3a ed.). Editora Hucitec, São Paulo, 157p.

Santos M 1997. A natureza do espaço (2a ed.). Editora Hucitec, São Paulo, 308p.

Secretaria Municipal de Planejamento/Departamento de Informações Técnicas 1999. Belo Horizonte.

Tancredi F 1979. Aspectos epidemiológicos do consumo de medicamentos psicoterápicos pela população de adultos do distrito de São Paulo. Dissertação de mestrado apresentada à Faculdade de Saúde Pública da USP.

Tardieu E 1995. Violência contra a mulher. Em busca da cidadania. Revista Plural. FUMEC, Belo Horizonte. 